\title{
Interactive comment on "Pre-inversion normal fault geometry controls inversion style and magnitude, Farsund Basin, offshore southern Norway" by Thomas Brian Phillips et al.
}

Thomas Brian Phillips et al.

thomas.b.phillips@durham.ac.uk

Received and published: 9 June 2020

Response to Review comments 1 - Pablo Rodriguez-Salgado

We thank the reviewer for their overall positive comment on the manuscript

"I consider that this manuscript contributes to improve the general understanding of the mechanisms and styles of basin inversion. More specifically, this manuscript contributes with new data and observations to the knowledge of the Late Cretaceous Cenozoic basin inversion and exhumation episodes in the Norwegian-Danish continental shelf. For that reason, I recommend publication of the manuscript after addressing

Printer-friendly version

Discussion paper 
few minor revisions."

We have responded to the individual comments and points raised by the reviewer be-

low and included the changes in the revised manuscript, as shown in the attached track changes document. Our responses are shown in italics with line numbers corresponding to changes in the track changes document with full markup shown.

Interactive

comment

Reviewer comments and responses:

1 ) Is the formation pressure of lower Cretaceous interval is hydrostatic in the 7 wells selected for this study? Have the authors performed any pre-conditioning of the sonic log curve (e.g. removal of anomalous DT readings)?

\section{Response}

No overpressure was recorded within the Lower Cretaceous interval across the wells used in this study, hence we assumed that the Lower Cretaceous interval formation pressure was hydrostatic. This is consistent with regional studies which also show no signs of overpressure in this interval (e.g. Japsen et al., 1998). Additional text, explaining the hydrostatic nature of the wells has been added to the revised manuscript (Line 245-249) The sonic log curve was pre-conditioned prior to being incorporated into our analyses (Line 268-269) in order to remove any anomalous values. We have now clarified the text on lines $255-258$ to better illustrate the pre-conditioning of the log prior to analysis.

2) Can the authors provide further details about the geometry and orientation of the strike-slip fault zone along the Farsund North Fault? Although some details are given in the line 257 "The proposed strike-slip fault continues towards Domain A to the west, and continues to the southeast, south of Domain C, to the east." I think the manuscript could be improved by indicating the location of the strike-slip faults in the Figure $5 a$.

\section{Response}

Discussion paper

Due to erosion at the base Jurassic unconformity, which removes related growth strata, 
the presence of the strike slip faults can only be determined by the offsets between older (i.e. Permo-Triassic), N-S- striking faults. We have revised manuscript to make this clearer (Line 128-130).

We can confirm the location of an older (i.e. pre-Cretaceous) strike-slip fault between offset N-S-striking faults, i.e. the fault partitioning the Farsund Basin and the fault along the western margin of the Varnes Graben. However, we can also show that no pre-cursor (i.e. Early-Middle Jurassic), strike-slip faulting occurred along the eastern segment of the Farsund North Fault, which initiated during the Early Cretaceous; we therefore suggest that the strike-slip system continued eastwards with a NW trend. A similar relationship occurs along the southern margin of the Farsund Basin, with the strike-slip system, the position and offset of which is constrained by the offset $\mathrm{N}$ S-striking faults, interpreted to continue north of an Early Cretaceous segment of the Fjerritslev South Fault with a NW-SE strike (Phillips et al., 2018). Additional information has been included in the manuscript (Lines 298-313, 320-330) to better illustrate our constraints on the overall geometry of the strike-slip fault system. We also link our observations made here from the northern basin margin to complementary observations from the southern basin margin (see Phillips et al., 2018).

We have added a proposed continuation of the strike-slip system to Figure 5 a to make the relationship between it and the eastern segment of the Farsund North Fault (Domain $\mathrm{C})$ clearer.

3) Line 270 - "We suggest that Domain C represents an Early Cretaceous segment of the Farsund North Fault, which propagated away from a pre-existing segment (Domain A) during the Early Cretaceous, with Domain B situated between the two segments." I completely agree. However, I think that segmentation along the Farsund North Fault is an important point and it could be further developed in the text. Is there any evidence of fault segmentation in the throw-distance profile shown in the Fig. 5b? For example, displacement patterns in this figure show throw maxima in the central part of the domains $\mathrm{A}$ and $\mathrm{C}$ decreasing towards the domain $\mathrm{B}$. Also, a similar throw pattern 
is observed between the domains $C$ and $D$. Could these patterns reflect different kinematically linked segments? Is there any relay ramp observed between the domains $A$ and $C$ and the domains $C$ and $D$ ? In the TWT structure map (Fig 5a) the authors show the Farsund North Fault as a continuous structure. Can the authors show the fault segments mentioned in the text (e.g. lines 270 and 349)? Also, can these segments be shown in the interpreted seismic sections (Figs $5 \mathrm{a}$ and $8 \mathrm{a}$ )?

Interactive

comment

Response

We agree that segmentation along the Farsund North Fault, as represented by the present distribution of throw, is an important point that was underexplored in the initial manuscript. In the revised manuscript we discuss in greater detail the geometry and distribution of throw along this fault 1 (Lines 299-301; 344-348).

We note throw maxima in the centre of domains $A$ and $C$, and suggest that these likely reflect segmentation of the initial fault, particularly as the eastern fault segment did not reactivate a pre-existing strike slip fault (see response to point 2). Relay ramp segmentation is likely present between Domain B and Domain C. We suggest that the segment in Domain C propagated away from Domain B (where we know a strikeslip precursor fault was present, see point 2) during the Early Cretaceous, rather than representing a segment that subsequently linked with the one in Domain $B$.

Domain D largely covers the Agder slope, east of the Farsund North Fault, although the eastern termination of the eastern fault segment (i.e. the segment that characterises Domain C) extends into the western end of Domain D (Line 351).

4) I understand that whereas both (fault) segments were active at least since Early Cretaceous times, there is no evidence that the Farsund North Fault was active during Carboniferous-Permian times. Is there any other evidence of Carboniferous-Permian activity (i.e. growth of the sequences) recorded by any other E-W-striking faults in the area? I think this could be an important point to be added to the conclusions.

Printer-friendly version

Discussion paper 
Extensional faults defining the Farsund Basin are largely not present during preZechstein extension (See Figure 3), in contrast to elsewhere along the SorgenfreiTornquist Zone, where faults were active during Carboniferous-Permian extension. We can also confirm that the eastern segment of the Farsund North Fault was Early Cretaceous or younger in age.

We note that the western segment of the Farsund North Fault was likely active during Early-Middle Jurassic strike-slip activity, with the Farsund North Fault showing a similar geometric and kinematic relationship to that of the Fjerritslev Fault System along the southern basin margin and propagating away from the strike-slip structure (see response to point 2). However, due to erosion at the BJU across the Upper Terrace of the Farsund Basin, we are unable to determine whether this area and associated faults experienced earlier, Carboniferous-Permian activity. We note that Carboniferous-Permian extension has been documented elsewhere along the Tornquist Zone (e.g. Erlstrom et al., 1997), and is also documented to the west in the Egersund Basin (Jackson and Lewis, 2013) (Line 117).

We have revised the manuscript to better outline the evolutionary histories of the various fault segments and to also better convey the uncertainty regarding CarboniferousPermian activity along the Farsund North Fault, particularly along the western segment (Line 322-325, 442-445).

5) Is there a null-point observed in any of the Lower Cretaceous or older horizons along the Farsund North Fault? I think it is worth mentioning in the manuscript whether this observation is made or not.

\section{Response}

We do not identify a null point at any point along the Farsund North Fault as the magnitude of the initial extensional offset along the fault was much greater than the subse- 
quent reverse offset. Therefore, the fault displays net-extensional offset at all depths. We have included this important point in the revised manuscript (Line 417-419)

6) Whereas the authors interpret a Late Cretaceous age for the inversion and exhumation in the Farsund Basin (Line 419) I understand that magmatic underplating is the main uplift mechanism behind the Neogene exhumation episode (e.g. paragraph starting in Line 425). However, in some parts of the manuscript the authors include both the Late Cretaceous and Neogene episodes within the term basin inversion. As the term basin inversion implies that uplift is controlled by reverse reactivation of a preexisting fault system (Cooper et al., 1989). This excludes any other source of uplift not caused by compressional reactivation of pre-existing faults (Chadwick et al., 1993) I think therefore that the use of the term basin inversion in some parts of the manuscript should be revised.

\section{Response}

We agree with the points raised by the reviewer here that the term "basin inversion" should not be used to describe the Neogene uplift event, and that this event should be clearly distinguished from the earlier, Cretaceous event. Furthermore, as we are unable to distinguish between individual uplift pulses, including those that may have occurred earlier in the Paleogene, we now refer to 'Paleogene-Neogene uplift' rather than 'Neogene inversion' to encompass all post Cretaceous uplift (e.g. lines 102, 138, 495). We also agree with the reviewer regarding our mode general use of the term "basin inversion".

Following additional comments from reviewer 2, we have modified our usage of this term. We now refer to Late Cretaceous "compression" or "shortening", which we argue were expressed via a number of different mechanisms across the Farsund Basin, including basin inversion (which was explicitly associated reverse reactivation of basinbounding normal faults). This has been modified in the revised manuscript (e.g. Lines 30-42). 
Additional minor and textual changes have been completed throughout the manuscript.

Please also note the supplement to this comment:

https://se.copernicus.org/preprints/se-2020-27/se-2020-27-AC1-supplement.pdf

Interactive comment on Solid Earth Discuss., https://doi.org/10.5194/se-2020-27, 2020.

Interactive

comment 


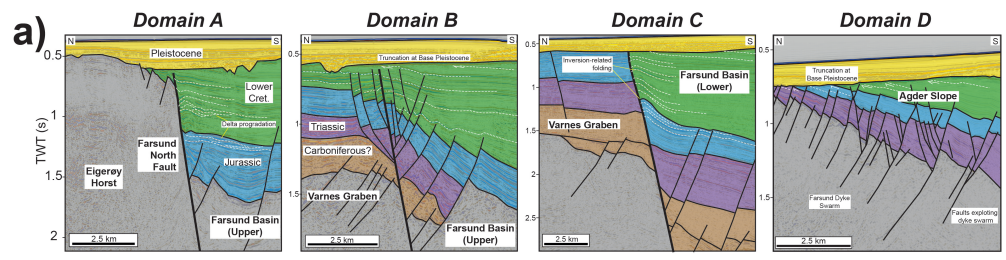

\section{SED}
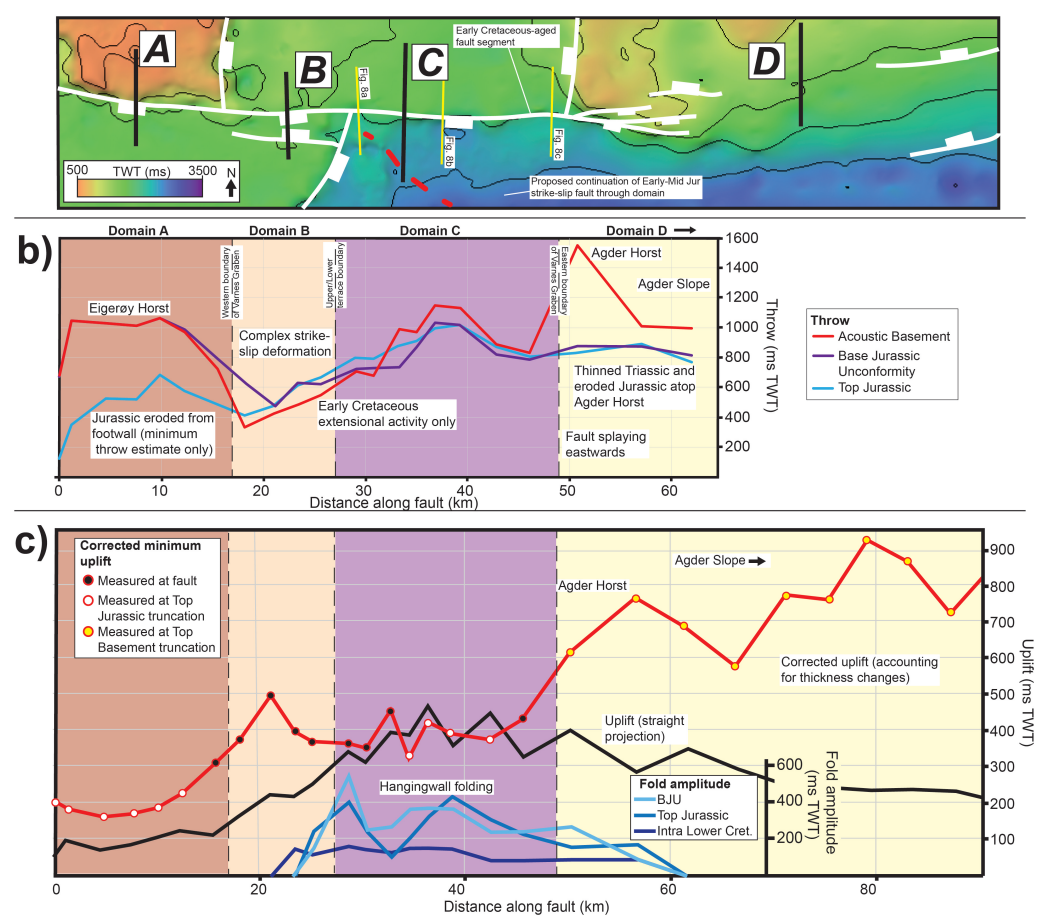

Printer-friendly version

Fig. 1. Revised Figure 5

Discussion paper 